\title{
Childhood Myositis Assessment Scale
}

National Cancer Institute

\section{Source}

National Cancer Institute. Childhood Myositis Assessment Scale. NCI Thesaurus. Code C121344.

An observational performance-based instrument developed to evaluate muscle strength, physical function, and endurance in children with juvenile idiopathic inflammatory myopathy. 